\title{
В ПОИСКАХ ПРИРОДЫ АНГЛИЙСКОГО НАЦИОНАЛИЗМА: ОТ ИМПЕРИИ ДО СОВРЕМЕННОСТИ
}

\author{
E.A. Атапин \\ Воронежский государственный университет, г. Воронеж, 394018, Россия
}

\begin{abstract}
Аннотация
В статье предпринята попытка выявить суть сложной природы английского национализма, проследив ее трансформацию с XVIII до начала XXI в. Установлены причины непопулярности проблемы национальной идентичности в английском историческом дискурсе, заключающиеся в отсутствии серьезных национальных потрясений с момента рождения современной британской государственности и относительной политической успешности, которая делала национальный самоанализ англичан излишним. Описано противоречие между «горизонтальным» восприятием англичан народами Британской империи и видением жителями Англии самих себя в вышестоящем положении по отношению к другим. Выявлен факт «сокрытия» английского национализма в британской идентичности, который соответствовал интересам империи. Для характеристики современного английского национализма привлекаются результаты исследований Центра английской идентичности и политики, особо подчеркивающие озабоченность англичан собственным политическим представительством в Соединенном Королевстве после деволюции. Сделан вывод об изменении характера английского национализма от гражданского англо-британского варианта (без акцента на английской этнической принадлежности) во времена существования империи до преимущественно этнического с акцентом на английской идентичности при крайне ограниченных возможностях гражданского выражения в начале XXI столетия.
\end{abstract}

Ключевые слова: английский национализм, национальная идентичность, Англия, Британская империя, Соединенное Королевство

В 1996 г., когда Англия принимала чемпионат Европы по футболу, в стране стало происходить нечто странное и неожиданное: повсеместно - на окнах домов и в витринах магазинов, на одежде болельщиков и на стадионах во время футбольных матчей - начал появляться флаг Святого Георгия. Почти не наблюдавшийся ранее, красный крест на белом фоне внезапно стал широко распространенным символом. Рост неподдельной популярности флага оценивался как беспрецедентный и первый отчетливо заметный признак пробуждения английского национализма [1]. При том, что в других частях Соединенного Королевства активное использование национальных флагов уже давно не вызывало удивления, для Англии возвращение старого символа явилось одним из самых важных и необычных политических событий последнего десятилетия XX в. 
Действительно, если национализм шотландцев, валлийцев и ирландцев воспринимается как естественная претензия этнических меньшинств на самоопределение и закрепление собственной национальной идентичности, то национализм англичан долгое время не замечался либо отрицался и до конца ХХ в. крайне редко выступал предметом научного интереса [2, p. 1].

Британские историки утверждают, что на протяжении нескольких столетий существования империи англичане не нуждались в национальной рефлексии. Для них ключевым фактором здесь выступала непрерывность поступательного развития их истории. Благодаря этой «бесшовной» непрерывности прошлое незаметно растворяется в настоящем, что затрудняет дифференциацию этих двух категорий, связывая их и создавая органическое целое. Такая преемственность имеет большое значение в построении концепции национальной идентичности. Как отмечал историк Герберт Баттерфилд, «поскольку англичане сохранили прочную связь со своим прошлым, им нет необходимости, в отличие от народов некоторых более молодых государств, заниматься поиском собственной идентичности. Им не нужно целенаправленно работать над формированием национального сознания или, подобно ирландцам, над возрождением национальной самобытности из обломков традиций и руин трагического прошлого» ${ }^{1}[3$, p. 114]. Так, после серьезного потрясения в виде гражданской войны XVII в. Англия не знала радикальных институциональных перемен, развиваясь по эволюционному пути.

По мнению Кришана Кумара, несмотря на трудности, связанные с промышленной революцией и массовой заменой сельского образа жизни городским, а также подъем к мировому господству и последующее падение, англичане имели все основания благодушно относиться к своей истории, особенно по сравнению со своими французскими соседями, пережившими череду революций и смен режимов [4, p. 425]. Подобная упорядоченность развития не способствовала эволюции самоанализа англичан прежде всего в вопросах национальной идентичности.

Формирование английской национальной идентичности должно рассматриваться, по крайней мере частично, как продукт имперских амбиций и имперского правления. Империя создавалась с претензией на построение универсального, более рационального и гуманного общества, чем в других государствах. Однако империя и нация сосуществуют непросто. Причина их фундаментального отличия кроется в том, что их представители осмысливают себя в разных плоскостях. Те, кто чувствует ответственность за империю, неизбежно ставят себя выше других народов, сталкиваясь с несогласием со стороны тех, кого они контролируют. Нации, напротив, склонны определять себя посредством горизонтальной дифференциации: они существуют не выше и не ниже других, а на одном уровне друг с другом. Бальц Энглер полагает, что именно этот конфликт между вертикальной и горизонтальной дифференциацией создает напряженность, которая подрывает попытки формулирования согласованного понятия английской национальности, тогда как именно оно позволило бы англичанам найти свое место среди других европейских народов [5, p. 338]. Вследствие этой напряженности одна и та же особенность может трактоваться совершенно по-разному с различных точек

\footnotetext{
1 Здесь и далее в цитатах перевод наш. - E.A.
} 
зрения. Если смотреть в вертикальном разрезе, то выходит, что англичане щедро предлагали миру то, что принадлежало им. Если же судить в рамках горизонтальной плоскости, то получается, что другие народы забирали у англичан их ресурсы.

Примечательно, что во времена Британской империи входившие в нее народы ощущали свою национальную идентичность как минимум на уровне дифференциации от прочих. Как писал в 1916 г. канадский историк Джордж Маккиннон Ронг, «канадец непохож на австралийца, и оба они отличаются от англичанина как физически, так и по образу своего мышления, поэтому австралиец совсем не обрадуется, если вы назовете его англичанином, так как он хочет быть самим собой, то есть именно австралийцем» [6, p. 50]. Любопытный факт при этом заключается в том, что, несмотря на различия, народы Британской империи в кризисных ситуациях проявляли солидарность друг с другом, особенно во время войн: «Вдумчивый австралиец или канадец будет отрицать, что испытывает привязанность к Британским островам, поскольку ощущает ее не больше, чем англичанин по отношению к Канаде. Каждому из них достаточно быть верным своим убеждениям, но в то же время их сплачивает то, что они придерживаются одинаковых взглядов на серьезные проблемы общегосударственного масштаба» [6, p. 50]. Наконец, Дж. Маккиннон Ронг полагал, что, хотя где-нибудь на западе Канады, в Австралии или Южной Африке можно не встретить ни одного англичанина, обнаружив вместо этого людей, критически относящихся к англичанам и желающих идти собственным путем, у проницательного британца это вызовет не тревогу, а радость. Исследователь подчеркивал, что Британская империя не являлась английской, а англичане представляли собой лишь один из многих ее народов. Целостность империи, по его мнению, была обеспечена за счет создания различных центров силы, примерно по одному на каждом континенте, таким образом, что каждый народ получил право на относительную свободу и независимость [6, p. 53].

Из вышеприведенных суждений следует вывести два важных замечания, касающихся восприятия национальной идентичности англичанами и другими народами, входившими в Британскую империю. Во-первых, народы заморской части империи в начале $\mathrm{XX}$ в. уже четко осознавали собственную национальную идентичность. Во-вторых, они воспринимали англичан как отдельную нацию. Отсюда выводится заключение, подтверждающее верность суждения о противоречивости взаимоотношений нации и империи. Так, если народы Британской империи исходили из «горизонтального» отношения наций друг к другу, воспринимая англичан как равных, то англичане - образующий империю народ исходили из «вертикального» соотношения себя и других, не имея традиции определения своей национальной идентичности и воспринимая себя именно как британцев, ответственных за судьбу империи.

Специфика самопонимания англичан была обусловлена тем, что они стали, по определению К. Кумара, «имперским» народом, которому был свойствен особый тип национализма - «миссионерский» [7, р. 5-7]. Именно по этой причине англичане приобрели «привычку» идентифицировать себя в качестве британцев. Здесь требуется уточнить, что британское государство было создано еще до начала индустриализации, американской революции 1765-1783 гг. и Французской 
революции, коренным образом изменившей политическую философию. В 1707 г. Британия стала протомодерновым монархическим государством, управляемым аристократической элитой. Благодаря созданию британского государства в доиндустриальное время, ему для обеспечения экономического развития не приходилось вступать в противоречие с гражданским обществом в той мере, в которой государства, появившиеся позднее, были вынуждены это делать [8, p. 19]. Как следствие, Британия оказалась страной, управлявшей, по сути, многообразием национальностей.

Для создания империи англичанам было необходимо выработать особую идентичность, которая стала бы объединяющей для всех входящих в нее народов. Сами создатели были вынуждены первыми примерить на себя эту новую идентичность, подавая пример всем остальным и сохраняя свое место в центре политической жизни огромного государства. Следовательно, в целях поддержания нормального функционирования империи этнический английский национализм был надежно «скрыт» политически необходимой британской идентичностью.

Англичане больше и чаще других народов Британской империи были склонны к объединению понятий «Англия» и «Британия», маскируя первое под вторым. Такое смешение объясняется политикой Великобритании. С момента создания государства в 1707 г. английские политики и государственные чиновники стремились защищать его суверенитет от внутренних и внешних угроз. Поэтому любой небританский национализм, в том числе и английский, не поощрялся. Соответственно, на протяжении большей части XIX и XX вв. английская идентичность выражалась через идеологию «британства».

Как полагает австралийский историк Бен Веллингс, тенденция к стиранию различий между государством и нацией уже присутствовала в английском национализме до образования британского государства. Расширение границ за пределы Британских островов предоставило английской идентичности еще одно измерение - имперское. В связи с этим, по мнению Б. Веллингса, не стоит пытаться объяснять отсутствие английского национализма наличием имперского дискурса, но следует вычленить английскую идентичность из «британства», сторонники которого считали понятия «Англия» и «Британия» синонимами, присваивая неанглийским территориям и народам английские определения и подпитывая этим англоцентричный британский национализм [9, p. 107]. Таким образом, дискурс английского национализма был по своей форме одновременно и имперским, и национальным, в чем нет противоречия.

Многонациональное устройство британского государства «скрывало» отличительные особенности проживающих в нем этносов по крайней мере до тех пор, пока Шотландия и Уэльс не добились самоуправления в 1999 г. Автономизация регионов Соединенного Королевства поставила англичан перед сложным вопросом о национальной идентичности. В Шотландии националисты смогли взять на вооружение сохранившиеся гражданские институты, такие как право, образование, церковь и средства массовой информации, превратив их в средства отличия Шотландии от остальной Великобритании. В Уэльсе валлийский язык выступил в роли маркера, отличающего его носителей от англичан. Местные политические институты могут также использоваться как маркеры идентичности в этих частях Соединенного Королевства. Однако в Англии после деволюции 
главными являются именно британские политические институты, вследствие чего способы выражения английского национализма не имеют других альтернатив, кроме как оставаться в рамках имперского дискурса [9, p. 106].

Рост английского национализма в первой половине XX в. был приостановлен двумя мировыми войнами, которые оказали консолидирующее влияние на британские национальные настроения, не позволив англичанам задаться вопросами о своей национальной идентичности. Многие факторы обеспечили устойчивость британской идеологии в тот период. Прежде всего империя, хоть и ослабленная в некоторых отношениях, продолжала играть заметную роль в общественном сознании, достигнув своего пика по территории и численности населения после Первой мировой войны. Кроме того, сюда же необходимо отнести британский характер экономики, подкрепленный программой промышленной национализации, рост популярности британского рабочего движения и Лейбористской партии, основание «Би-би-си» и планы по созданию государства всеобщего благоденствия $[10$, p. 51]. Спад популярности большинства британских общегосударственных проектов вкупе с другими событиями, такими как возрождение кельтского национализма, присоединение Великобритании к европейскому интеграционному проекту, секуляризация, глобализация и деволюция к началу XXI в. подорвали идею «британства» и создали условия для того, чтобы проблема английской национальной идентичности вышла в публичное поле.

В середине XX в. появилась еще одна причина для роста английского национализма. С упадком Британской империи, особенно после 1945 г., усилилась иммиграция. Однако миграционные притоки по территории Соединенного Королевства распределялись неравномерно, представляя собой наиболее серьезную проблему именно для Англии. Ответом на увеличившиеся объемы иммиграции стало движение за утверждение специфически английской идентичности, которое было инициировано крайне правыми организациями, такими как Британская национальная партия, Национальный фронт и Лига защиты Англии [11, p. 14].

В начале XXI в. вопросы английской идентичности начали серьезно исследоваться в классических английских университетах. Так, на базе Саутгемптонского университета профессором Джоном Денхэмом был создан Центр английской идентичности и политики, целью которого является глубокое изучение эволюции английского и британского типов идентичности и их политического выражения. Кроме того, Центр занимается вопросами местного и государственного управления в Англии, а также проблемами взаимодействия Англии с Соединенным Королевством в целом (CEIP).

Здесь уместно привести оценку современного состояния английского национализма, данную руководителем Центра английской идентичности и политики Дж. Денхэмом. По его заключению, это не «яростный национализм либеральных кошмаров» [12]. У этого национализма, по сути, нет политической партии и программы. Он также не может похвастаться поддержкой со стороны интеллигенции, самовыражением через культуру или зрелыми социальными институтами.

Конечно, не все жители Англии считают себя в первую очередь англичанами. Исследования Центра показали, что, хотя большинство граждан идентифицируют себя в равной степени и как англичан, и как британцев, около трети 
отдают предпочтение именно английской идентичности («скорее англичанин, чем британец») [12]. Неудивительно, что у осознающих себя преимущественно англичанами английские интересы выражены более отчетливо.

Однако в большинстве своем не эти люди находятся у власти в Англии. Они, как правило, проживают в сельской местности и не имеют высшего образования. В их число входят представители рабочего класса, являющиеся опорным электоратом Лейбористской партии в Англии, а также люди из сферы малого бизнеса. Если все они и испытывают ностальгию, то не столько по империи, сколько по месту, которое они когда-то занимали в центре национальной жизни. Власть в Англии сейчас принадлежит выпускникам университетов, тем, кто руководит корпоративным бизнесом, имеет влияние в сфере культуры и искусства, а также в средствах массовой информации и академических кругах. Влиятельные позиции с большей долей вероятности будет занимать меньшинство, считающее себя «скорее британцами, чем англичанами», чем идентифицирующие себя как «скорее англичане, чем британцы».

Последние меньше всего удовлетворены своим политическим представительством и вряд ли чувствуют понимание со стороны Вестминстера. Они желают, чтобы английские законы принимались английскими депутатами, а многие хотели бы, чтобы в Англии был свой парламент. Они возмущены механизмом государственного финансирования деволюционных регионов, известным как «формула Барнетта» (“Barnett formula”), согласно которому на бедные английские регионы тратится меньше государственных расходов в расчете на душу населения, чем на Шотландию. Многие полагают, что во взгляде на проблемы, связанные с национальной системой здравоохранения, университетскими сборами, социальной помощью, образованием, Европейским союзом и иммиграцией, интересы Англии отличаются от интересов Великобритании в целом. Девять из десяти считают важным наличие политической партии, которая бы отстаивала интересы Англии, при этом половина из них не могут сказать, какой должна быть эта партия [12].

Наконец, те, кто считает себя «скорее англичанами, чем британцами», полагают, что и Евросоюз, и Соединенное Королевство действуют против интересов той конкретной Англии, которую они считают отстраненной от власти. Такое противоречие между британским истеблишментом и англичанами связано со стремлением последних к власти, представительству и демократии, которое в любой другой стране, скорее всего, воспринималось бы как должное. Английский национализм не обязательно должен быть регрессивным или правым по своей сути. Наоборот, он мог бы заложить фундамент программы последовательного и демократического политического проекта. Но без четкой артикуляции и координации интересы англичан остаются на зачаточной стадии, а английский национализм видится мощной, но изменчивой и непредсказуемой силой. Для сохранения целостности Соединенного Королевства английские избиратели должны быть уверены в его гибкости и политической дееспособности наравне с избирателями в Уэльсе, Шотландии и Северной Ирландии.

Важнейшее положение, которое следует выделить из позиции Дж. Денхэма, состоит в том, что английский национализм в начале XXI в. развивается в этнической форме в условиях острого дефицита возможностей для его гражданского 
проявления. Несомненно, важно сохранить целостность Соединенного Королевства, но для этого необходимо привести непредсказуемую стихию английского национализма в гражданское русло, обеспечив легитимные каналы для трансляции политической воли англичан.

Действительно, допускать отделение Англии от Великобритании было бы неразумным и ослабляющим государственную власть обеих сторон шагом. Английские политические традиции всегда были не национальными, а скорее наднациональными. Английская идентичность имеет тесную связь с Британией и британцами. Трудно представить себе Англию без Британии, еще труднее осуществить подобный проект. Как утверждает К. Кумар, «Англия для англичан» - это нереалистичная и неразумная стратегия [13, p. 469].

Таким образом, природа английского национализма претерпела изменения по сравнению с имперскими временами. Если в эпоху Британской империи он был гражданским, «скрытым» под проектом глобальной британской идентичности без этнических проявлений, которые бы угрожали подрыву империи, то к концу XX столетия ситуация повернулась на 180 градусов. Распад Британской империи в середине XX в. и последующая передача части парламентских прав местным органам Уэльса, Шотландии и Северной Ирландии поставили англичан в новое для них положение. Привыкшие быть ядром более крупных государственных образований, при этом идентифицируя себя с ними, не имевшие традиции глубокого размышления о сущности своей национальной идентичности, англичане столкнулись с не возникавшими ранее вопросами, ответы на которые большинству европейских народов приходилось искать еще в прошлых столетиях. Чувствуя, что британская идентичность больше не выполняет функцию того общего связующего элемента в рамках наднационального объединения, в котором Англия играет главную роль, англичане оказались в положении, прямо противоположном тому, в котором они находились в период существования Британской империи. Английский национализм приобрел этнические черты, лишившись вне рамок связи с британской идентичностью гражданского выражения.

Можно сделать вывод, что противоречивая природа английского национализма способствует усложнению процесса его изучения, подчас заставляя сомневаться в самом факте его существования. Исторически сложившееся несоответствие характера английского национализма формам его проявления отчасти связано с имперским прошлым англичан, а отчасти - с тем политическим положением, в котором оказалась Англия в современном Соединенном Королевстве после деволюции. Оно еще сильнее выделяет английский национализм на фоне большинства континентальных европейских «национализмов», делая его более многогранным, любопытным и привлекательным объектом для изучения.

\section{Источники}

CEIP - Centre for English Identity and Politics. - University of Southampton. - URL: https://www.southampton.ac.uk/ceip/index.page, свободный. 


\section{Литература}

1. Harris P. Just what sort of nation might the English seek to create? // Aeon Essays. 9 August 2016. - URL: https://aeon.co/essays/just-what-sort-of-nation-might-the-englishseek-to-create, свободный.

2. English R. Is There an English Nationalism? - London: Inst. Public Policy Res., 2011. $9 \mathrm{p}$.

3. Butterfield H. The Englishman and His History. - Cambridge: Cambridge Univ. Press, 1945. - $142 \mathrm{p}$.

4. Kumar K. English and French national identity: Comparisons and contrasts // Nations Natl. - 2006. - V. 12, No 3. - P. 413-432. - doi: 10.1111/j.1469-8129.2006.00247.x.

5. Engler B. Englishness and English studies // European English Studies: Contributions towards the History of a Discipline / Ed. B. Engler, R. Haas. - Leicester: Engl. Assoc. Eur. Soc. Study Engl., 2000. - P. 335-348.

6. Wrong G. The growth of nationalism in the British Empire // Am. Hist. Rev. - 1916. V. 22, No 1. - P. 45-57.

7. Kumar K. Empire and English nationalism // Nations Natl. - 2006. - V. 12, No 1. - P. 1-13. doi: 10.1111/j.1469-8129.2006.00227.x.

8. Nairn T. The Break-up of Britain: Crisis and Neo-Nationalism. - London: New Left Books, 1977. - 368 p.

9. Wellings B. Empire-nation: National and imperial discourses in England // Nations Natl. 2002. - V. 8, No 1. - P. 95-109. - doi: 10.1111/1469-8219.00040.

10. Bond R. Review: English national identity // Scott. Aff. - 2004. - No 48. - P. 50-55.

11. Gibbons T., Malcolm D. Sport and English National Identity in a 'Disunited Kingdom'. London: Routledge, 2017. - 232 p.

12. Denham J. English nationalism is misunderstood // The Irish Times. - 2019. - 13 Aug. URL: https://www.irishtimes.com/opinion/english-nationalism-is-misunderstood-1.3984982, свободный.

13. Kumar K. Negotiating English identity: Englishness, Britishness and the future of the United Kingdom // Nations Natl. - 2010. - V. 16, No 3. - P. 469-487. - doi: 10.1111/j.1469-8129.2010.00442.x.

\footnotetext{
Атапин Евгений Александрович, аспирант кафедры истории зарубежных стран и востоковедения Воронежский государственный университет Университетская пл., д. 1, г. Воронеж, 394018, Россия E-mail: atapinvrn@mail.ru
} 
UCHENYE ZAPISKI KAZANSKOGO UNIVERSITETA. SERIYA GUMANITARNYE NAUKI (Proceedings of Kazan University. Humanities Series)

2021, vol. 163, no. 3, pp. 31-40

ORIGINAL ARTICLE

doi: 10.26907/2541-7738.2021.3.31-40

\title{
In Search of the Nature of English Nationalism: From the Empire to the Modern Era
}

\author{
E.A. Atapin \\ Voronezh State University, Voronezh, 394018 Russia \\ E-mail: atapinvrn@mail.ru
}

Received April 7, 2021

\begin{abstract}
This paper attempts to reveal the essence of the complex nature of English nationalism by tracing its transformation from the 18 th century to the early 21 st century. The reasons for unpopularity of the problem of English national identity in the English historical discourse (such as the absence of serious national upheavals since the birth of modern British statehood and the relative political success, which made the English national introspection superfluous) were discussed. A contradiction between the "horizontal" perception of the English by the peoples of the British Empire and the view held by the citizens of England on their superiority over others was analyzed. The fact of "concealment" of English nationalism in the British identity to pursue the interests of the empire was revealed. To contrast contemporary English nationalism with that of the imperial era, the research by the Centre for English Identity and Politics highlighting the English concern about their own political representation in the United Kingdom after the devolution was cited. It was concluded that the nature of English nationalism has changed from a civil AngloBritish version without an emphasis on English ethnicity during the empire's existence to a predominantly ethnic one with a focus on English identity with extremely limited opportunities for civil expression in the early 21 st century.
\end{abstract}

Keywords: English nationalism, national identity, England, British Empire, United Kingdom

\section{References}

1. Harris P. Just what sort of nation might the English seek to create? Aeon Essays, 2016, Aug. 9. Available at: https://aeon.co/essays/just-what-sort-of-nation-might-the-english-seek-to-create.

2. English R. Is There an English Nationalism? London, Inst. Public Policy Res., 2011. 9 p.

3. Butterfield H. The Englishman and His History. Cambridge, Cambridge Univ. Press, 1945. 142 p.

4. Kumar K. English and French national identity: Comparisons and contrasts. Nations Natl., 2006, vol. 12, no. 3, pp. 413-432. doi: 10.1111/j.1469-8129.2006.00247.x.

5. Engler B. Englishness and English studies. In: European English Studies: Contributions towards the History of a Discipline. Engler B., Haas R. (Eds.). Leicester, Engl. Assoc. Eur. Soc. Study Engl., 2000, pp. 335-348.

6. Wrong G. The growth of nationalism in the British Empire. The American Historical Review, 1916, vol. 22, no. 1, pp. 45-57.

7. Kumar K. Empire and English nationalism. Nations and Nationalism, 2006, vol. 12, no. 1, pp. 1-13. doi: 10.1111/j.1469-8129.2006.00227.x.

8. Nairn T. The Break-up of Britain: Crisis and Neo-Nationalism. London, New Left Books, 1977. $368 \mathrm{p}$.

9. Wellings B. Empire-nation: National and imperial discourses in England. Nations and Nationalism, 2002, vol. 8, no. 1, pp. 95-109. doi: 10.1111/1469-8219.00040. 
10. Bond R. Review: English national identity. Scottish Affairs, 2004, no. 48, pp. 50-55.

11. Gibbons T., Malcolm D. Sport and English National Identity in a 'Disunited Kingdom'. London, Routledge, 2017. 232 p.

12. Denham J. English nationalism is misunderstood. The Irish Times, 2019, Aug. 13. Available at: https://www.irishtimes.com/opinion/english-nationalism-is-misunderstood-1.3984982.

13. Kumar K. Negotiating English identity: Englishness, Britishness and the future of the United Kingdom. Nations and Nationalism, 2010, vol. 16, no. 3, pp. 469-487. doi: 10.1111/j.14698129.2010.00442.x.

Для цитирования: Атапин Е.А. В поисках природы английского национализма: от империи до современности // Учен. зап. Казан. ун-та. Сер. Гуманит. науки. - 2021. - Т. 163 , кн. 3. - С. 31-40. - doi: 10.26907/2541-7738.2021.3.31-40.

For citation: Atapin E.A. In search of the nature of English nationalism: From the empire to the modern era. Uchenye Zapiski Kazanskogo Universiteta. Seriya Gumanitarnye Nauki, 2021, vol. 163, no. 3, pp. 31-40. doi: 10.26907/2541-7738.2021.3.31-40. (In Russian) 